\title{
Sense of Belonging in School as a Protective Factor Against Drug Abuse Among Native American Urban Adolescents
}

\author{
Maria Napoli \\ Flavio Francisco Marsiglia \\ Stephen Kulis
}

\begin{abstract}
This article presents the results of a study conducted with 243 Native American students who were part of a multi-ethnic sample of adolescents attending middle school in a large urban center in the Southwest region of the United States. Native adolescents who felt a stronger sense of belonging in their school were found to report a lower lifetime use of alcohol and cigarettes, lower cigarette and marijuana use in the previous month, lower frequency of current use of these substances, fewer substances ever used, and a later age of initiation into drug use than other Native students. Research implications are discussed in relationship to school environment, culturally-grounded prevention curricula, and school social work practice. (A rticle copies available for a fee from The Haworth Document Delivery Service: 1-800-HA WORTH. E-mail address: $<$ docdelivery@haworthpress.com>Website: <http://www.HaworthPress.com> (C) 2003 by The Haworth Press, Inc. All rights reserved.]
\end{abstract}

Maria Napoli, PhD, is Assistant Professor, School of Social Work ( E-mail: maria. napoli@asu.edu). Flavio Francisco Marsiglia, PhD, is Associate Professor and Director, Southwest Interdisciplinary Research Consortium, School of Social Work. Ste phen Kulis, PhD, is Professor, Department of Sociology, Arizona State University, Tempe, AR.

The research reported in this article was funded in part by a grant of the National Institute on Drug Abuse/National Institutes of Health (1 R24 DA13937-01A1/5 R01 DA05629-07) and an Arizona State University College of Public Programs Dean's Incentive Grant.

Journal of Social Work Practice in the Addictions, Vol. 3(2) 2003

http://www.haworthpress.com/store/product.asp?sku=J160

(C) 2003 by The Haworth Press, Inc. All rights reserved. 
KEYWORDS. Native Americans, adolescents, drug use, school belonging

\section{INTRODUCTION}

Native Americans are a very diverse cultural group. Not only are there many intertribal differences, but Native Americans as a group have the highest intermarriage rates of any ethnic group in the U.S. (U.S. Cen sus Bureau, 1993). Approximately 60\% of married Native Americans are married to non-Indians (Eschback, 1995). These complex lineages may explain the wide range of answers Native children provide when asked about their parents' ethnicity (Eschback, 1995). Such ethnic diversity, the experience of genocide, the legacy of colonialism, and the historical pressures to assimilate may have weakened the sense of ethnic identity of urban Native youth (Schaefer, 2001). The efforts of some Native peoples to regain their culture has been described as enculturation, distinguishing it from the more common concept of acculturation or assimilation into the majority culture (Zimmerman et al., 1996). The process of enculturation appears to be vital for younger urban Native Americans' sense of ethnic identity. Schools play an important role in either assisting in or drawing away Native students from the process of enculturation.

Of the approximate two million Native people in the United States, between 300,000 and 400,000 are of school age, representing about one percent of the nation's student population (U.S. Census Bureau, 2001). Eighty-five percent of Native students across the nation attend public schools and share overall low academic achievement and high drop out rates (Rhodes, 1998; Stokes, 1997).

Some authors argue that related to their lower academic achievement, Native youth have a higher rate of substance abuse than other adolescent populations (Mackesy-Amiti \& Fendrich, 2000; Mitchell \& $O^{\prime}$ Nell, 1998; Herring, 1994), and an alcoholism rate that is double the national average (Garrett, 1999).

Use rates for Native youth vary by type of substance, geographic region, and tribal membership, but alcohol use rates are consistently high(Caetano, Clarck \& Tam, 1998). Native youth also start using alcohol, tobacco and other drugs at an earlier age than the general population. One third of Native youth begin using alcohol by the time they are eleven years old and $78 \%$ have done so by age 17, compared with $53 \%$ of the general population (Herring, 1994). In addition, $40 \%$ of the ado- 
lescent participants (ages 14-18) in a multi-tribal study reported using marijuana at least once in the last month (Novins \& Mitchell, 1998).

Research studies tend to emphasize the already well documented high drug use rates of Native youth while neglecting the exploration of drug resistance behaviors. There is a tendency to overlook the Native adolescents who do not use drugs and are able to successfully delay drug use until adulthood (Beauvais, 1998; Hawkins et al., 1992). The present study aims at advancing our understanding of this resistance phenomenon by hypothesizing that a stronger sense of belonging in school has a protective effect against drug use for Native American adolescents. This assumption is based on an ecological risk and resiliency approach that argues that welcoming environments support resiliency (Bogenschneider, 1996). This article explores the possible buffer effect that sense of belonging in school may have against drug use for urban Native American adolescents in the Southwest.

\section{NATIVE CULTURES AND ENCULTURATION}

Although Native Americans represent a diverse group of cultures, speaking 253 languages, and organized into 558 tribes, a sense of Indianess binds them together. They share similar world-views, a his tory of colonialism, and cultural standards and meanings that are based on common core values (Garrett, 1999). The experiences of genocide and forced assimilation have eroded in different degrees that sense of Indianess. Enculturation, not to be confused with acculturation, describes the efforts Native peoples make to regain their ancestral cultures (Zimmerman et al., 1996). Acculturation, often through immigration, is the process through which an individual's attitudes and behaviors change as a result of exposure to a different society (Lessenger, 1997). Native American communities did not migrate; they were conquered. In most cases their ancestral lands were taken away and too often their cultures were destroyed. The new culture was forced upon them through the reservation system, boarding schools, Christianity, Capitalism, and an alien form of government. These processes have generated in some the opposite of ethnic pride-a sense of ethnic shame or embarrassment-which has been identified as a risk factor for drug abuse among Native youth (Kulis, Napoli \& Marsiglia, 2002).

Enculturation is proposed as a means of reconnecting to ancestral norms and values and of coping with the generational trauma emerging from a history of loss. Schools are key environments to facilitate encul- 
turation by helping Native youth achieve a balance between education advancement and cultural preservation (Ambler, 2000; Callahan \& McIntire, 1994). The assumption is that Native students who feel welcome by their schools are better able to function in both the Native and non-Native worlds and will live healthier lives.

\section{An Approximation to Sense of Belonging in School}

The experience of being part of a community of learning has been described using different terms such as belonging in school, having a sense of attachment, a sense of identification, and a sense of member ship (Hagborgh, 1998). For the purpose of this study, "school belonging" is utilized to capture the experience of being part of a school community. Belonging in school has been defined as the extent of personal membership, respect and support students feel in school (Hagborg, 1998). Middle school students typically explain belonging in school as having friends in class, having quality peer interactions, actively participating in class activities, obtaining good grades, and feeling like part of the class when the teacher is firm, active, interesting, and the material is meaningful (Williams \& Downing, 1998). Techniques such as friendship activities, peer supports, and support networks have been identified as being particularly effective in the creation of classroom communities where a sense of belonging is nurtured (Korinek, Walther-Thomas, McLaughlin, \& Williams, 1999).

A sense of belonging in school has been identified as a particularly relevant resiliency factor for school success among younger adolescents (Bornholt, 2000). Generally, students reporting a strong sense of belonging have better grades, spend more time on homework, and are more motivated toward educational achievement than students with a low sense of belonging in school (Hagborg, 1998; Roeaser, Midgley, \& Urdan, 1996). Affiliation with a subgroup of peers within the classroom also has been found to be strongly associated with a sense of belonging (Schnorr, 1997).

Although developing a strong sense of belonging in school is important to all students, it appears that it is a particularly strong factor in academic achievement for ethnic minority students. A study conducted with Mexican American students identified this sense of belonging in school as the only significant predictor of academic resilience (Gonzalez \& Padilla, 1997). Although a multiethnic study found that White male students had the lowest levels of identification with school (Voelkl, 1996), students from majority culture may not need to question 
if their schools reflect their culture, since standard educational curricula tends to reflect it.

The weakened sense of belonging in school experienced by some Native students as they reach adolescence has been attributed to an uncertainty about their place within the White world (Hussong, Bird, \& Murphy, 1994). Racist attitudes and behaviors can be a strong deterrent to the development of supporting school environments where Native youth feel welcome and where they might develop a strong sense of belonging (Palmer \& Cooke, 1996). Moreover, older generations within the family with memories of the coercive system of Native boarding schools may contribute to a sense of caution, wariness or distrust of today's school systems, particularly those dominated by non-natives.

A strong sense of belonging in school together with a positive sense of ethnic pride appear to buffer Native youth from drug use (Oetting \& Beauvais, 1991). However, these two factors can be in conflict with each other when Native American children attend school outside of the reservation (Marsiglia et al., 1998). These adolescents have been found to be vulnerable to increased familial stress and cultural conflicts encountered in mainstream educational settings (Machamer \& Gruber, 1998). Native American youth in general have been described as having to develop a bicultural approach to social relations and communication to cope with their sense of rejection and the pressure to conform to two or more different cultures (Moran, 1999). Classroom approaches that are culturally responsive have been found to increase students' sense of belonging in school and promote academic achievement (Stokes, 1997; Van Hamme, 1996).

This study hypothesizes that a stronger sense of belonging in school will also result in a delay in the onset of drug use and/or a lower drug use rate among Native students. Sense of belonging in school will be ex plored through an overarching question about the students' perceptions of their membership in their school. The analysis controls for possible intervening factors such as age and school achievement (Colodarci, 1983; Ehlers et al., 2001), as well as gender, socioeconomic status, and mixed ethnic heritage (Kandel, 1995; Vega \& Gil, 1998).

\section{METHOD}

Subjects. This article analyzes self-reported responses from 243 seventh grade students who self-identify as Native American. They are a sub-sample of a larger sample of 4,630 middle school students who 
were enrolled in school districts located within a large urban area of Arizona in Fall of 1998. All 45 middle schools within the city were recruited for the study, and 35 schools spread over 9 school districts agreed to participate. Every 7 th grader within these schools was selected as a participant in the study. The participating schools are ethnically diverse: 79 percent of their student population self-identify as non-majority, including 70 percent who identify as Hispanic and 9 percent as African American. Although all of the respondents attended schools located within a metropolitan area, some of the schools serve Native American reservations directly adjacent to city boundaries. Consequently, this sample includes urban Native American students as well as some semi-urban Native American students from reservations who are attending predominately non-Native schools.

Instruments. University trained survey proctors administered a 45minute written questionnaire, available on one form both in English and Spanish. In all but two schools the surveys were administered during regular school hours in a 7th grade science, health, or home room class. Students were informed that this was a university research project and were guaranteed confidentiality. The students' regular teachers were not present during the survey administration. All students present the day of survey administration agreed to complete the questionnaire.

Demographic profile of participants. Excluding those who failed to report key demographic information (gender, race/ethnicity, age), there were 243 respondents who self-identified as Native American. These students ranged from 11 to 15 years of age, with 88 percent being 12 or 13 years old. There were nearly equal numbers of boys (48 percent) and girls (52 percent). Most of the students were from lower income families and received either a free (67 percent) or reduced price school lunch (10 percent). A substantial minority (45 percent) indicated that a language other than English was spoken at home at least occasionally, but only 6 percent indicated that they "mostly" or "exclusively_" spoke a language other than English at home.

Variables. A series of Likert-type items captured students' substance use behaviors and their sense of belonging in school. Students also completed a core demographic section in which they were asked to identify with one or more ethnic group. Question wording and index construction are detailed in the Appendix.

Drug use in lifetime, last month, and frequency of use. A 'set of dependent variables was constructed from questions about the frequency of recent drug use, modeled after questionnaire items used by Flannery, Vazsonyi, Torquati, and Fridrich (1994). These measures were chosen 
due to their developmental specificity for the age group being studied. In addition, these measures are similar to scales used in other large studies of early adolescent drug use (e.g., Kandel, 1995; Newcomb \& Bentler, 1986). Students were asked to indicate how much over their lifetime and in the past month they had: smoked cigarettes or used any other tobacco product, drank alcohol, and smoked marijuana. Students were also asked how frequently they had used alcohol, tobacco and marijuana in the last month. Because the distributions were highly skewed toward low rates of drug use, we transformed the categories of the original responses by calculating their natural log. We also calculated two composite measures: the number of different types of drugs ever used by the student (alcohol, cigarettes, marijuana, smokeless tobacco, uppers/speed/"meth," inhalants, or "hard" drugs like cocaine, heroin, and LSD); and the average frequency of use last month for three more commonly used substances (alcohol, cigarettes, marijuana).

A ge of initial drug use. Information from three questions was combined to identify the earliest age that students began using alcohol, cigarettes, and marijuana. Analyses of this outcome are restricted to students who indicated they had used at least one of these three substances.

School belonging. The major independent variable is measured by responses to the question "I really feel that I belong in this school." This variable was recoded so it is scored from (1) low ("strongly disagree") to (5) high ("strongly agree").

Multivariate analysis also modeled the effect of self-identifying with a "Native American only" versus a "multi-ethnic" identity. In addition to "Native American," respondents could self-identify as any of the following: "Mexican American or Chicano/a," "Other Hispanic," "White," "African American," or "Asian or Pacific Islander [API]." The largest ethnic groupings were: (1) Native American only (28\%), (2) Native American and Mexican heritage, including those also claiming a 3rd or 4th identity (39\%), (3) Native American and White (some with other non-Mexican identities as well) (21\%), and (4) Native American and a non-Mexican and non-White identity (i.e., African American, API and other, 12\%).

Several control variables are entered into the multivariate analyses. Gender is coded as a dummy variable with females as the reference group. Two items that measure the extent to which the students speak English ( 1 = never, $2=$ seldom, $3=$ half and half, $4=$ mostly, $5=$ exclusively) with family and friends were summed to create an indicator of bi-cultural experience and acculturation. The student's "usual grades in 
school," rated on a Likert scale from 0 (mostly F's) to 9 (mostly A's), are a self-reported global assessment of academic performance. Socioeconomic status is roughly distinguished with a dummy variable contrasting those who do and do not receive a free or reduced price school lunch. Finally, age is measured in years.

A nalysis strategy. We present results that predict the degree to which students use drugs, using strength of sense of belonging in school and ethnicity ("Native only" versus "multi-ethnic Native") as predictors, and controlling for gender, English versus other language use, academic performance, socioeconomic status, and age. Significant group differences are analyzed through an examination of bivariate correlations and ordinary least squares regressions. The regressions examine the role of school belonging in drug use, whether-mixed identity Native American students are different from those identifying solely with their Native heritage, and, employing interaction terms, whether a sense of belonging in school is a more powerful factor in preventing drug use for students identifying exclusively as Native American than for Native students reporting a mixed ethnic heritage.

\section{STUDY FINDINGS}

Descriptive statistics and selected correlations for all dependent and independent variables are presented in Table 1. The means suggest that the typical student has used alcohol in his or her lifetime more than any other substance, followed by cigarettes and then marijuana. Alcohol also is the most heavily used in the previous month, followed by marijuana. The frequency of use in the prior month was similarly low across all three substances, and the self-reported age of initiation into drug use was around 11.5 years.

In Table l, the bivariate correlations between drug outcomes and the predictors suggest that a stronger sense of belonging in school has a possible protective or resiliency effect against drug use. Correlations indi cate that a sense of belonging is significantly related to lower lifetime use of alcohol and cigarettes; these students reported that they had: (a) drank less alcohol, smoked fewer cigarettes, and used fewer different types of drugs over their lifetimes; (b) smoked fewer cigarettes in the last month; (c) used alcohol and all three most commonly used substances combined less frequently in the last month; and (d) became initiated into drugs at a later age. 
TABLE 1. Means, Standard Deviations, and Correlations for the Main Variables in the Analysis

\begin{tabular}{|c|c|c|c|c|}
\hline & \multirow[b]{2}{*}{$\mathrm{N}$} & \multirow[b]{2}{*}{ Mean } & \multirow[b]{2}{*}{$\begin{array}{l}\text { Standard } \\
\text { deviation }\end{array}$} & $\begin{array}{l}\text { Correlations } \\
\text { with: }\end{array}$ \\
\hline & & & & $\begin{array}{c}\text { Sense of } \\
\text { belonging } \\
\text { in school }\end{array}$ \\
\hline Sense of belonging in school & 243 & 2.06 & 0.92 & $1.000^{* * *}$ \\
\hline Alcohol use-life time amount & 243 & 0.87 & 0.76 & $-0.215^{\star \star \star}$ \\
\hline Cigarettes use-life time amount & 243 & 0.65 & 0.75 & $-0.192^{* *}$ \\
\hline Marijuana use-life time amount & 241 & 0.42 & 0.66 & 0.057 \\
\hline Alcohol use-last 30 days amount & 243 & 0.40 & 0.66 & 0.019 \\
\hline Cigarettes use-last 30 days amount & 243 & 0.25 & 0.53 & $-0.139^{*}$ \\
\hline Marijuana use-last 30 days amount & 240 & 0.32 & 0.63 & 0.103 \\
\hline Alcohol-frequency of use last 30 days & 241 & 0.26 & 0.48 & $-0.128^{*}$ \\
\hline Cigarettes-frequency of use last 30 days & 243 & 0.22 & 0.46 & 0.121 \\
\hline Marijuana-frequency of use last 30 days & 241 & 0.23 & 0.49 & 0.093 \\
\hline Average use of all three substances last 30 days & 243 & 0.24 & 0.40 & $-0.130^{\star}$ \\
\hline Substance of choice-frequency of use & 243 & 0.41 & 0.40 & 0.128 \\
\hline Number of drugs ever used & 243 & 1.51 & 1.51 & $-0.143^{*}$ \\
\hline Age of initiation in drug use & 242 & 11.50 & 5.50 & $0.197^{\star *}$ \\
\hline
\end{tabular}

${ }^{*} p<.05 ;{ }^{* *} p<.01 ; \cdot{ }^{* *} p<.001$

The multivariate regression models in Table 2 include strength of sense of belonging in school as a predictor as well as a dummy variable modeling the ethnic/racial group self-identification of the respondent, and the interaction between those two variables. They also introduce controls for gender, English language use with family and friends, school achievement, socioeconomic status, and age when predicting student drug use behavior.

Native American students with a stronger sense of belonging reported they had used lesser amounts of alcohol, fewer cigarettes and a smaller number of different substances over their lifetime; smoked fewer cigarettes and less marijuana in the prior month; currently use alcohol and cigarettes (and all three principal substances combined) less frequently; and, started using drugs at a later age. Native American students of mixed ethnic heritage are not different from those self-identifying exclusively as Native American except that the latter have significantly lower lifetime use of alcohol than the former. For many substances, largely due to the limited $\mathbf{N}$, the differences for Native only versus 
TABLE 2. Regression Analysis of Rates of Drug Use (Unstandardized Regression Coefficients)

\begin{tabular}{|c|c|c|c|c|c|c|c|c|c|c|c|c|}
\hline \multirow[b]{2}{*}{ Predictor } & \multicolumn{3}{|c|}{ Life Time Use } & \multicolumn{3}{|c|}{ Amount of Use Last 30 Days } & \multicolumn{3}{|c|}{ Frequency of Use Last 30 Days } & \multirow{2}{*}{$\begin{array}{l}\text { Average } \\
\text { Frequency } \\
\text { of Drug } \\
\text { Use Last } \\
30 \text { Days }\end{array}$} & \multirow{2}{*}{$\begin{array}{c}\text { Number } \\
\text { of Drugs } \\
\text { Ever } \\
\text { Used }\end{array}$} & \multirow{2}{*}{$\begin{array}{c}\text { Age of } \\
\text { Initiation } \\
\text { into Drug } \\
\text { Use }\end{array}$} \\
\hline & $\begin{array}{l}\text { Alcohol } \\
b\end{array}$ & $\begin{array}{l}\text { Cigarettes } \\
\text { b }\end{array}$ & $\begin{array}{l}\text { Marijuana } \\
\text { b }\end{array}$ & $\begin{array}{l}\text { Alcohol } \\
b\end{array}$ & $\begin{array}{l}\text { Cigarettes } \\
b\end{array}$ & $\begin{array}{l}\text { Marijuana } \\
\underline{\mathrm{b}}\end{array}$ & $\begin{array}{l}\text { Alcohol } \\
\underline{b} \\
\end{array}$ & $\begin{array}{l}\text { Cigarettes } \\
\underline{\mathrm{b}}\end{array}$ & $\begin{array}{l}\text { Marijuana } \\
\underline{\mathrm{b}}\end{array}$ & & & \\
\hline $\begin{array}{l}\text { Sense of Belonging } \\
\text { in School }\end{array}$ & $-0.181^{* *}$ & $-0.169^{\star *}$ & -0.081 & -0.099 & $-0.139^{\star *}$ & $-0.117^{*}$ & $-0.087^{\star}$ & $-0.106^{\star *}$ & -0.081 & $-0.089^{*}$ & $-0.409^{* *}$ & $0.644^{*}$ \\
\hline $\begin{array}{l}\text { Native American } \\
\text { Identity Only }\end{array}$ & $-0.285^{\star \star}$ & -0.063 & -0.008 & -0.147 & -0.062 & 0.029 & -0.081 & -0.042 & 0.007 & -0.041 & -0.178 & 0.756 \\
\hline $\begin{array}{l}\text { Interaction: Belong. } \\
\text { x Nat.Am. }\end{array}$ & -0.004 & 0.038 & 0.104 & 0.027 & 0.162 & 0.073 & 0.018 & 0.122 & 0.041 & 0.058 & 0.220 & 0.175 \\
\hline $\begin{array}{l}\text { SES-Free/Reduced } \\
\text { School Lunch }\end{array}$ & -0.154 & -0.101 & -0.013 & -0.073 & -0.023 & 0.040 & -0.039 & $-0.024 a$ & 0.037 & -0.013 & -0.209 & 0.081 \\
\hline $\begin{array}{l}\text { Use English with } \\
\text { Family \& Friends }\end{array}$ & -0.052 & -0.033 & -0.047 & -0.019 & -0.051 & -0.061 & -0.038 & -0.040 & -0.046 & -0.043 & -0.195 & 0.144 \\
\hline $\begin{array}{l}\text { Grades-School } \\
\text { Achievement }\end{array}$ & $-0.081^{* *}$ & $-0.062^{*}$ & $-0.094^{* * *}$ & -0.044 & -0.034 & $-0.048^{*}$ & $-0.035^{*}$ & -0.028 & $-0.035^{*}$ & $-0.032^{*}$ & $-0.142^{*}$ & 0.197 \\
\hline $\begin{array}{l}\text { Gender }(\text { Male }=1 ; \\
\text { Female }=0)\end{array}$ & -0.059 & -0.073 & 0.048 & 0.052 & 0.052 & 0.069 & 0.038 & 0.015 & 0.044 & 0.032 & 0.066 & -0.211 \\
\hline Age & 0.130 & $0.218^{* *}$ & $0.135^{*}$ & 0.022 & 0.043 & 0.067 & 0.018 & 0.067 & 0.079 & 0.061 & $0.394^{*}$ & -0.297 \\
\hline Intercept & $1.123^{\star \star \star}$ & $0.789^{\star * *}$ & $0.431^{* * *}$ & $0.497^{\star \star *}$ & $0.273^{\star * *}$ & $0.282^{* *}$ & $0.315^{\star * *}$ & $0.277^{\star \star \star}$ & $0.210^{* *}$ & $0.274^{* * *}$ & $1.804^{* * *}$ & $5.319^{\star \star *}$ \\
\hline N & 235 & 235 & 233 & 235 & 235 & 232 & 235 & 235 & 233 & 235 & 235 & 234 \\
\hline $\mathrm{R}^{2}$ & 0.133 & 0.101 & 0.104 & 0.045 & 0.063 & 0.057 & 0.055 & 0.055 & 0.057 & 0.067 & 0.082 & 0.066 \\
\hline
\end{tabular}

${ }^{\star} \mathrm{p}<.05 ;{ }^{* \star} \mathrm{p}<.01 ;{ }^{* * *} \mathrm{p}<.001$ 
multi-ethnic Natives are in the same direction and of appreciable magnitude but are just shy of being statistically significant.

The interaction effects of sense of belonging in school and mixed ethnic identity versus exclusively Native American identification are not significant for any drug outcome. Other control variables such as school performance, gender, socioeconomic status, and language use provide further insights into normative differences among the students. Students with higher grades report a lower lifetime use of alcohol, cigarettes and marijuana, and fewer use of different types of drugs than those reporting lower school achievement. Not surprisingly, these students also indicated that their use of marijuana during last month was less frequent and of lesser amounts, as was their use of alcohol and all three major substances combined. Native boys are not significantly different than Native girls in avoiding drug use.

Older 7th grade students (ages 14-15) had a significantly higher lifetime :use of cigarettes and marijuana than younger students (ages 11-13). However, there were no statistically significant differences be tween older and younger students in recent use (last month) of any of the substances. The use of English at home or the socioeconomic status were also found not to be significant factors in the students' use of drugs.

\section{DISCUSSION}

The drug use rates reported by the respondents support the premise that a strong sense of belonging in school has a buffering effect on the drug use behaviors and norms of Native students (Hagborg, 1998; Stachowski, 1998; Little-Soldier, 1989 \& 1997; Bogenschneider, 1996; Vadas, 1995; Davis, 1994; Ward \& Barton, 1995, Robey, 1999; Stokes, 1997; Rhodes, 1988). On the other hand, school isolation and disconnectedness appear to contribute to higher rates of drug use and to earlier initiation into drugs (Hussong et al., 1994).

Mixed ethnicity background (identifying as being of Native American and some other ethnicity) versus Native American only background were found not to influence the relationship between sense of belong ing in school and drug use behaviors and norms. School belonging had the same protective effect on both groups. This finding is particularly important when working with urban and semi-urban Native students presenting high rates of mixed ethnic heritage (Eschback, 1995). Enculturation may explain in part the lack of significant differences be- 
tween these two groups. In a Southwest context, some Native students of mixed or diffused heritage may find sufficient support to engage in a process of enculturation. Further research, utilizing existing measures of enculturation (Zimmerman et al., 1996) is needed in order to further explore these possible associations.

Confirming previous findings, Native students with higher academic performance reported lower drug use rates (Roeaser et al., 1996). It is clear from our findings, however, that sense of belonging plays a pro tective role against drug use even after accounting for differences in school achievement. Moreover, among the students in the study, good grades were not strongly associated with a stronger sense of belonging in school (Pearson correlation coefficient $=+.05$ ). Further, it is impossible to determine the cause and effect relationship between these two factors with the cross-sectional data from this study.

Future research with other samples is needed to explore further the relationship between sense of belonging in school and school achievement for Native students. Perhaps ethnographic research may better il luminate the meaning of these adolescents' experiences, identifying the definition of a "successful" academic experience that may strengthen the sense of belonging in school, or showing how students who feel welcome in the first place become more likely to achieve academically. A second level of mediating analysis should follow to determine how sense of belonging in school and academic achievement, independently and in combination, may play a mediating role in drug use by influencing integration into peer networks and the development of anti-drug norms.

Study Limitations and Recommendations for Future Research

Due to the exploratory nature of the study, the findings cannot be generalized to other Native American adolescents. However, this initial exploration of belonging in school and its possible relationship to drug use behaviors and norms merit further research. The fact that sense of belonging in school was measured by one overarching item seriously limits the depth of the analysis. Future efforts need to address the possible multi-dimensionality of school belonging. Biculturalism needs to be defined and measured from a Native perspective and constructs such as enculturation need to be operationalized and included in future models. The lack of contextual data on the school's culture, teachers' ethnicity, ethnic breakdown of the school, neighborhood characteristics, and geographic proximity to Indian reservations, further limits the inter- 
pretation and generalizability of these findings. Survey research alone cannot capture the multi-dimensionality of the phenomenon. A mixed method approach is suggested as a means to advance our knowledge about the impact of sense of belonging in school on the drug use behaviors and norms of Native adolescents.

Developing a culturally grounded learning experience that embraces the Native holistic view of life is recommended. If Native youth hear facts about their history that more accurately reflect their ancestral ex perience they have an opportunity to feel more connected to the school environment in a positive way. If teachers are cognizant of the particular learning style of Native students, opportunities for increased academic achievement and higher retention rates might be created. Hence, the sense of belonging to one's school can be a protective factor against drug abuse.

Based on the findings of additional studies, courses of action need to be taken to enhance what works in addition to changing what is not working. It is time to move away from the traditional deficit model used to explain the lack of academic success of some Native American students. More needs to be learned from our academically successful and drug-free Native youth. Their experiences need to serve as the basis for innovative culturally grounded prevention programs.

Additional intervening variables need to be considered in future research. For example, comorbidity, genetics (children of alcoholics), and learning disabilities could have an effect on the strength of the sense of belonging to school that Native and other youth experience.

Implications for Social Work

Social workers have much to contribute in this process by serving as competent cultural mediators between Native communities and schools. Social workers in partnership with universities can play an important role in designing and evaluating innovative programs that capitalize on the resiliency of Native students and support for their psychosocial needs.

School social workers have the unique advantage of working with students, teachers, administrators, and families. Since formal social work education prepares social workers to function in various roles, they are in a position to contribute-in collaboration with Native community resources-to curriculum change and developing training programs for teachers and administrators. They need to obtain information from students about how the school can be more effective in meeting 
their needs. They also need to meet with agencies and counselors that work in the area of Native addictions. Programs such as the Red Road to Recovery, The Healing Forest Model Program, Cultural Substance Abuse Programs, The Medicine Wheel and the 12 Steps (www.whitebison.org) and mentorship programs can be assessed for appropriateness by school social workers and introduced to school faculty, students, and administrators. Collaboration efforts with tribal colleges and tribal educational services can facilitate the development of mentorship programs.

In many ways, the school social worker is a pivotal person to develop and coordinate information that can integrate these issues surrounding Native students' academic achievement and substance abuse. In fact, not only do school social workers have the opportunity to bring the vision of the Native community into educational settings, but also it is their obligation to do so. In light of the high school drop out rate and increases in substance abuse among Native students, school social workers have no other choice but to "step up to the plate" and work toward creating change.

\section{REFERENCE}

Beauvais, F. (1998). American Indians and alcohol. Alcohol Health \& Research World, 22, 4, 253-259.

Bogenschneider, K. (1996). An ecological risk protective theory for building prevention programs, policies, and community capacity to support youth. Family Relations, 45(2), 127-138.

Caetano, R., Clarck, C.L., \& Tam, T. (1998). Alcohol consumption among racial ethnic minorities: Theory and research. Alcohol Health \& Research. World, 22, 4, 233 , 241.

Colodarci, T. (1983). High school dropout among Native Americans. Journal of American Indian Education, 23, 15-22.

Davis, P. (1994). Thoughts on Dine Education. Journal of Navajo Education, 12, 1, 15-17.

Ehlers, C.L., Wall, T.L., \& Garcia-Andrade, C. et al. (2001). Effects of age and parental history of alcoholism on EEG findings in mission Indian children and adolescents. Alcoholism-Clinical and experimental Research, 25, 5, 672-679.

Eschback, K. (1995). The enduring and vanishing American Indian: American Indian population growth and intermarriage in 1990. Ethnic and racial studies, 18, 1, 89-108.

Flannery, D. J., Vazsonyi, A.T., Torquati, J., \& Fridrich, A. (1994). Ethnic and gender differences in risk for early adolescent substance use. Journal of Youth and Adolescence, 23,2, 195-213. 
Gonzalez, R., \& Padilla, A.M. (1997). The academic resiliency of Mexican American high school students. Hispanic Journal of Behavioral Sciences, 19(3), 301-317.

Hagborg, W.J. (1998). An investigation of a brief measure of school membership. Adolescence, 33, 461-468.

Hawkins, J.D., Catalano, R.F., \& Miller, J. Y. (1992). Risk and protective factors for alcohol and other drug problems in adolescence and early adulthood: Implications for substance abuse prevention. Psychological Bulletin, 112, 64-105.

Herring, R.D. (1994) Substance use among Native American Indian youth: A selected review of causality. Journal of Counseling and Development, 72(6), 578-584.

Hussong, R., Bird K., \& Murphy C.V. (1994). Substance abuse among American Indian women of child bearing age. Indian Health Services Provider, 19 (12), 196-9.

Kandel, D.B. (1995). Ethnic differences in drug use: Patterns and paradoxes. In GJ. Botvin. S. Schinke \& M.A. Orlandi (Eds.), Drug Abuse Prevention With Multiethnic Y outh (pp. 81-104). Thousand Oaks, CA: Sage.

Korinek, L., Walther-Thomas, C., McLaughlin, V.L., \& Williams, B.T. (1999). Creating classroom communities and networks for student support. Intervention in School and Clinic, 35, 1, 3-8.

Kulis, S., Napoli, M., \& Marsiglia, F.F. (2002). The effects of ethnic pride and biculturalism on the drug use norms of urban American Indian adolescents in the Southwest. Social Work Research, 26, 2, 101-112.

Lessenger, L. H. (1997). Use of acculturation rating scale for Mexican Americans 11 with substance abuse patients. Hispanic Journal of Behavioral Sciences, 19, 387-398.

Little-Soldier, L. (1989). Cooperative learning and the Native American Student. Phi Delta Kappa, 46, 161-163.

Little-Soldier, L. (1997). Is there an "Indian" in your classroom? Working successfully with urban Native American students. Phi Delta Kappa, 78, 650-653.

Machamer, A.M., \& Gruber, E. (1998). Secondary school, family, and educational risk: Comparing American Indian adolescents and their peers. Journal of Educational Research, 91, 6, 357-369.

Mackesy-Amiti, M.E., \& Fendrich, M. (2000). Trends in inhalant use among school students in Illinois: 1993-1995. American Journal of Drug and Alcohol A buse, 26, 4,569-590.

Marsiglia, F.F., Cross, S., \& Mitchell, V. (1998). Culturally grounded group work with adolescent American Indian students. Social Work with Groups, 2, 69-82. ,

Mitchell, C.M., \& O'Nell, T.D. (1998). Problem and conventional behaviors among American Indian adolescents: Structure and validity. Journal of Research on Adolescence, 8, 1, 97-122.

Moran, J.R. (1999). Preventing alcohol use among urban American Indian youth: The Seventh Generation program. Journal of Human Behavior in the Social Environment, 2, 1/2, 51-67.

Nêwcomb, M., \& Bentler, P. (1986). Substance use and ethnicity: Differential impact of peer and adult models. The Journal of Psychology, 120, 1, 83-95.

Novins, D.K., \& Mitchell, C.M. (1998). Factors associated with marijuana use among American Indian adolescents. Addiction, 93, 11, 1693-1702. 
Oetting, G.R., \& Beauvais, F. (1991). Orthogonal cultural identification theory: The cultural identification of minority adolescents. International Journal of the Addictions, 25, 655-685.

Palmer S., \& Cooke, W. (1996). Understanding and countering racism with first nations children in out-of-home care. Child Welfare, 75, 6, 709-725.

Rhodes, R. (1998). Holistic teaching/learning for Native American students. Journal of American Indian Education, 6, 1, 21-29.

Robey, C. (1999). Traditional teachings help in teaching reforms. Sho-Ban News, 23, 41, 1-4.

Roeaser, R.W., Midgley, C., \& Urdan, T.C. (1996). Perceptions of the school psychological environment and early adolescents' psychological and behavioral functioning in school: The mediating role of goals and belonging. Journal of Educational Psychology, 88, 3, 408-422.

Schaefer, R.T. (2000). Racial and ethnic groups (8th edition.). Upper Saddle River, NJ: Prentice-Hall.

Schnorr, R.F. (1997). From enrollment to membership: "Belonging" in middle and high school classes. Journal of the Association for Persons with Severe Handicaps, $22,1,1-15$.

Stachowski, L. (1998). Student teachers' efforts to promote self-esteem in Navajo pupils. The Educational Forum, 62, 341-346.

Stokes, S. (1997). Curriculum for Native American students: Using Native American values. The Reading Teacher, 50, 7, 576-584.

United States Bureau of the Census (1993). We the First Americans. WE-5. Washington, DC: U.S. Government Printing Office.

Vadas, R. (1995). Assessing the relationship between academic performance and attachment to Navajo culture. Journal of Navajo Education, 12, 2, 16-25.

Van Hamme, L. (1996). American Indian culture and the classroom. Journal of American Indian Education, 36, 21-36.

Vega, W.A., \& Gil, A.G. (1998). Drug use and ethnicity in early adolescence. New York: Plenum Press.

Voelkl, K.E. (1996). Measuring students' identification with school. Educational and Psychological Measurement, 56, 5, 760-770.

Ward, A., \& Barton, J. (1995). Making schools intentionally inviting to Native American students. Contemporary Education, 67. 1, 33-37.

Williams, L.J., \& Downing, J.E. (1998). Membership and belonging in inclusive classrooms: What do middle school students have to say? Journal of the Association for. Persons with Severe Handicaps, 23, 2; 98-110.

Zimmerman, M.A., Ramirez Valles, J., Washienko, K.M., Walter, B., \& Dyer, S. (1996). The development of a measure of enculturation for Native American youth. American Journal of Community Psychology, 24, 2, 295-310.

RECEIVED: 03/07/02

REVISED: 08/05/02

ACCEPTED: $11 / 12 / 02$ 


\section{APPENDIX. Questionnaire Items and Index Construction}

\section{Lifetime Drug Use}

"How many drinks of alcohol have you had in your entire life?" Natural log of original Likert scale responses: 1 = "None" to 10 = "Over 100 drinks."

"How many cigarettes have you smoked in your entire life?" Natural log of original Likert scale responses: 1 = "None" to 10 = "More than 20 packs."

"How many times have you used marijuana in your entire life?" Natural log of original Likert scale responses: $1=$ "Never" to 10 = "Over 30 times."

An additive index of the number of seven different types of drugs ever used in lifetime: alcohol, cigarettes, smokeless tobacco, marijuana, "hard drugs" (cocaine, crack, LSD, PCP, heroin), "uppers" (speed, crystal meth), and inhalants (glue, spray, gas).

\section{CurrentDrug Use}

"How many drinks of alcohol you had in the past 30 days?" Natural log of original Likert scale responses: 1 = "None" to 10 = "More than 30 drinks."

"How many cigarettes have you smoked in the past 30 days?" Natural log of original Likert scale responses: 1 = "None" to 10 = "More than 2 packs."

"How many `hits' of marijuana have you had in the past 30 days?" Natural log of original Likert scale responses: 1 = "Never' to 10 = "Over 40 hits."

Frequency of recent drug use for three separate substances: "How many days in the last 30 days have you... (1) ... "had alcohol to drink?" (2) . . . "Smoked cigarettes?" (3) . . "smoked marijuana?" Transformed by calculating the natural log of original Likert scaled responses: $1=$ "None" to $6={ }^{\circ} 16-30$ days."

Average frequency of use: mean of the three above items.

\section{Age of Initiation.}

"How old were you when you first . . ." " . . . had a drink of alcohol?" ". . . smoked a cigarette?" ". . smoked marijuana?" Coded from 7 (or younger) to 14 (or older). Combined by selecting the youngest age at which any of the three substances was used.

\section{Sense of Belonaina.}

"| really feel like I belong in this school." 1 = "Strongly disagree," 2 = "Disagree," 3 = "Agree," 4 = "Strongly agree." 